\section{Tendencias opuestas. Introducción}

Marcia Veneziani *

Resumen: Esta segunda publicación entre Parsons The New School for Design y la Universidad de Palermo, se enfoca en las fuerzas directrices de las variadas tendencias opuestas que con mayor fuerza se observan en los comportamientos sociales en la actualidad. Considerando las diferencias y similitudes entre ambos países, se analizó cómo se podrían expresar-mediante el diseño- aquellas demandas emergentes y las fuerzas dinámicas implicadas en esas tendencias contradictorias y, al mismo tiempo, paradójicas.

Esas controversias tienen su base en estudios previos de otros autores y en la evidencia empírica que se pone de manifiesto en los variados ensayos publicados aquí. La metodología empleada en el abordaje revela, una vez más, la necesidad de proponer nuevas reglas de juego a la hora de acercarse al objeto de estudio dentro del campo del Diseño y de la Comunicación. Los autores argentinos que actúan en las diversas disciplinas del área, aceptan el desafío de colocar bajo la lupa las huellas que se han encontrado respecto de las fuerzas directrices incoadas, y que se manifiestan en los cambios culturales y en las experiencias que se exteriorizan en la sociedad. Todo ello analizado bajo la mirada de la sociología, el diseño de interiores, la ecología, el diseño de indumentaria, la fotografía, la publicidad, el arte y, por supuesto, la pedagogía.

Palabras clave: diseño - tendencias opuestas - sociología - diseño de interiores - ecología - diseño de indumentaria - fotografía - publicidad - arte -pedagogía.

[Resúmenes en inglés y portugués en las páginas 20-21]

${ }^{*}$ Doctora en Comunicación Social y Licenciada en Publicidad (USAL). Docente de la Universidad de Palermo en el Departamento de Investigación y Producción de la Facultad de Diseño y Comunicación, integrante del Equipo de Evaluación de Proyectos de Graduación y miembro del Comité de Posgrado y del Doctorado en Diseño. Profesora en el Doctorado en Diseño en la Universidad de Palermo. Es Profesora Titular de Marketing de la Moda y Sociología de la Moda y ha sido Profesora Titular en la Maestría en Comercialización y Comunicación Publicitaria en otras Instituciones. Es Miembro del Comité Editorial de la Revista ZoneModa Journal, Universitá di Bologna, Italia, desde julio de 2013.

Cuando se planteó la idea de elaborar una segunda publicación entre Parsons The New School of New York y la Universidad de Palermo, los coordinadores que representan en esta 
instancia a ambas instituciones -y a la hora de encarar la temática para la presente publicación- decidimos enfocarnos en las fuerzas directrices de las variadas tendencias opuestas que con mayor fuerza se observan en los comportamientos sociales en la actualidad. Tal decisión no fue el producto de un capricho o del azar, sino más bien el resultado de profundos debates acerca de esas disposiciones presentes y cada vez más crecientes en nuestra contemporaneidad.

Considerando, una vez más, las diferencias y similitudes entre ambos países, se plantearon interrogantes que abrieron la cuestión, y que a la vez contemplaran el abanico de las tendencias a explorar con mayor detenimiento. Se analizaron cómo se podrían expresar -mediante el diseño- aquellas demandas emergentes y, por lo tanto, las fuerzas dinámicas implicadas en esas tendencias contradictorias y, al mismo tiempo, paradójicas.

Esas controversias tienen su base en estudios previos de otros autores y en la evidencia empírica que se pone de manifiesto en los variados ensayos publicados aquí.

La metodología empleada en el abordaje revela, una vez más, la necesidad de proponer nuevas reglas de juego a la hora de acercarse al objeto de estudio dentro del campo del Diseño y de la Comunicación.

Así, los estudiosos argentinos que actúan en las diversas disciplinas del área, aceptaron el desafío de realizar un trabajo colectivo con los colegas norteamericanos, con el fin de colocar bajo la lupa las huellas que se han encontrado respecto de las fuerzas directrices incoadas, y que se manifiestan en los cambios culturales y en las experiencias que se exteriorizan en la sociedad.

Todo ello analizado bajo la mirada de la sociología, el diseño de interiores, la ecología, el diseño de indumentaria, la fotografía, la publicidad, el arte y, por supuesto, la pedagogía.

Florencia Bustingorry en su artículo titulado: Moda y distinción social. Reflexiones en torno a los sentidos atribuidos a la moda, examina la relación entre el fenómeno de las tendencias y los sentidos que socialmente se construyen alrededor de ella, haciendo hincapié sobre todo en los contextos de producción, circulación, consumo y apropiación. Para la autora definir las tendencias implica una marcada e innata complejidad dada la esencia misma de la moda: su carácter polisémico y contradictorio. Empleando para su ensayo un abundante marco teórico, la autora -haciendo referencia al campo de acción y su constitución-sostiene que: "como una red de relaciones, de fuerzas contrapuestas que se oponen en una lucha por la legitimación de sus posiciones, también se constituye en un espacio de confrontación por la conservación o la subversión de sus principios".

Paola Gallarato propone, en Buscando el vacio, una reflexión acerca de la posibilidad de considerar el espacio ocioso como un cuerpo con una delimitación propia -y no como un hueco al que hay que llenar- y al que se le otorga generalmente la calidad de necesidad, concebido casi como una urgencia por colmar. La autora se aventura a jugar y a experimentar con los límites del espacio proyectual, y postula un cambio de enfoque: un espacio concebido como "entidad habitable", ya que permitiría la posibilidad de su misma materialización. En sus mismas palabras: "Según la mitología, lo que no está ocupado por el ser -y el ser presupone una presencia física y visible- tiene que hospedar algo oculto...” y luego especifica: "Es el histórico horror vacui, literalmente miedo al vacío, que se resuelve en llenar obsesivamente cada espacio, cada rincón, por el temor de dejarlos desocupados". 
José E. Putruele y Marcia Veneziani en Sustentabilidad, diseño y reciclaje presentan un ensayo en el que convergen variadas disciplinas, con el fin de validar las pertinencias requeridas en los estudios académicos. La intención de los autores es iniciar una reflexión acerca de la reutilización de materiales y su vinculación específica con el diseño. Para ello, el estudio explora en el concepto de sustentabilidad y reciclaje, presentando dos casos: uno de diseño de interiores y otro de diseño de indumentaria. La visión antropológica se vuelve, por lo tanto, más que necesaria para comprender el vínculo entre el ser humano y el medio ambiente. En suma, se expone la tensión entre dos ejes: el consumismo y la sustentabilidad.

Verónica Fiorini en su artículo titulado Tendencias de consumo, innovación e identidad en la moda. Transformaciones en la enseñanza del diseño latinoamericano, profundiza en los conceptos del título y analiza al mismo tiempo su vinculación con la didáctica del diseño y el mercado de la indumentaria. La autora hace referencia a "una cierta tensión discursiva que se evidencia entre influencias globales y costumbres o improntas locales". Y su propósito es el de exhibir "algunas problemáticas vinculadas a los aspectos metodológicos en términos de construcción de los significados en los proyectos de diseño excediendo las fronteras de lo estrictamente lingüístico". Al mismo tiempo, el texto pretende mostrar la tensión entre los conceptos mencionados anteriormente, en la elaboración de las marcas con identidad propia en la Argentina.

Leandro Allochis en el ensayo titulado La mirada lúcida. Desafíos en la producción y recepción de imágenes en la comunicación contemporánea, pone en evidencia el eje desestructuración - estructuración de las imágenes. Analiza a su vez, la tendencia que Erner denominara oportunamente como "neomanía" por parte de los observantes, con el fin de descomponer la estructura estética y a la vez simbólica, de lo que el autor entiende como rasgo distintivo en relación a los medios masivos y las representaciones simbólicas involucradas en el proceso de decodificación de las imágenes de poder y valores, asociados a la masculinidad hegemónica y patriarcal. El texto alude que el vivir en la iconósfera implica nuevos retos "tanto para receptores como para productores del discurso visual y solicita una interpelación crítica por parte de los profesionales de la comunicación, para comenzar a ensayar respuestas y proponer nuevos vínculos para con los públicos contemporáneos" Andrea Pol por su parte, se ocupa de la publicidad en Brand 2020. El futuro de las marcas. La autora plantea un desplazamiento del rol del gerente de marca al de cazador de tendencias. Para ello, elabora un mapa de tendencias para las marcas del 2020 realizando una interpretación de los "fenómenos significativos" manifestados a partir de cambios sociales y culturales. El eje de polos opuestos que se plantea en el escrito -en materia de tendencias- es el de "emergente" y "dominante". Al plantear escenarios posibles, en el ensayo se deja de manifiesto que "el mapping del escenario de las marcas en el próximo decenio no puede escindirse del macro-contexto social, económico, demográfico, ecológico, político, climático, etc. Las variables incontrolables del macro entorno influyen indefectiblemente en toda estrategia de branding".

Valeria Stefanini escribe en esta ocasión: La puesta en escena. Arte y representación. El artículo propone una reflexión acerca de la resignificación a partir de la fotografía que se recrea y que a su vez representa otras obras pictóricas o fotográficas. La autora se enfoca en las producciones de Julia Margaret Cameron, Cindy Sherman, Orlan y de Nicola Costan- 
tino. Las composiciones de los artistas mencionados, remiten a la cita y a la apropiación. Es decir, el eje de opuestos sería la foto de la puesta en escena en contraposición a la foto como mimesis de la realidad. La toma de la obra ajena, le consentiría al fotógrafo -en palabras de la autora- "vincularse y ser parte de esa obra, modificarla y dotarla de nuevas posibilidades de sentido, es un acto de empatía, de conexión con algo distante que me construye y me modifica".

Teresita Bonafina en Lo austero: ¿un estilo de vida o una tendencia en la moda?, analiza, desde la perspectiva de autores como Bourdeau, Bauman, Merton y Schifman, entre otros, dos conceptos que se contraponen en el mundo de la moda: la austeridad y la ostentación. Desde una perspectiva sociológica, la autora observa al consumidor de moda, lo interpela en un juego dialéctico y por momentos provocador. En el artículo la socióloga destaca que la tendencia hacia la austeridad "tiene que ver con estabilizar a la persona y solidificar sus decisiones, más allá de la pertenencia o la distinción, un estilo del vestir que de sensación de atemporalidad, eternidad por encima de lo efímero".

Patricia Doria propone en su escrito: Poética, inspiración y tendencias en Diseño de Indumentaria, una reflexión acerca del diseño del vestido vinculándolo con una trama de actividades que va más allá de la simple intuición. La autora profundiza en la poética para explicar aquello que trasciende lo puramente estético. Sostiene que la demanda de creatividad en el campo del diseño de indumentaria, surge "como respuesta a la necesidad de los diseñadores de alejarse de las tendencias, de encontrar un contrapunto entre tendencias globales representadas en las producciones masivas y la necesidad de diseñar lo único y exclusivo".

Carlos Caram en su artículo Pedagogía del diseño: el proyecto del proyecto desafía la actividad en el aula, tanto del docente como del estudiante. El autor, interpela a lo largo de todo el texto al lector, invitando tanto a repensar la actividad pedagógica como a romper con preconceptos. El ensayo pone de manifiesto la tensión entre aquello que "viene con el estudiante", es decir su capacidad cognitiva y su talento, y lo que aprende en el aula. La pedagogía del diseño es considerada como una suerte de "red" a la que es imposible separar de "la contextualización social y como contraparte al talento del aprendiz no debe de ninguna manera desechar los saberes previos, al contrario, debe fundarse en estos para resignificar los conocimientos y los aprendizajes".

Summary: This second publication developed by Parsons The New School for Design and the University of Palermo focuses on the driving forces of the various opposing trends that are observed more strongly in social behavior today. Considering the differences and similarities between the two countries, we discussed how they could express -by designthose emerging demands and the dynamic forces involved in these both contradictory and paradoxical tendencies.

Such disputes are based on previous studies of other authors and on the empirical evidence that araises from the various essays published here. The methodology used in the approach reveals, once again, the need to propose new rules when approaching the subject of study within the field of Design and Communication. The Argentine authors 
working in the various disciplines of the area accepted the challenge of placing under the microscope the footprints found regarding this instituted guideline forces and manifested in the cultural changes and experiences that are externalized in society. All this is analyzed under the lenses of sociology, interior design, ecology, fashion design, photography, advertising, art and pedagogy.

Key words: design - opposite trends - sociology - interior design - ecology - fashion design - photography - advertising - art-pedagogy.

Resumo: Esta segunda publicação entre Parsons The New School of Design e a Universidade de Palermo enfoca-se nas forças diretrizes das variadas tendências opostas que com maior força podem se ver hoje nos comportamentos sociais. Considerando as diferenças e similitudes entre ambos os paises, se analisou como se poderiam expressar, mediante o design, as demandas emergentes e as forças dinâmicas implicadas nessas tendências contraditórias.

Essas controvérsias estão baseadas em estudos prévios de outros autores e na evidencia empírica que se põe de manifesto nos variados ensaios aqui publicados. A metodologia usada na abordagem revela, mais uma vez, a necessidade de propor novas condições na hora de aproximar-se ao objeto de estudo no campo do design e da comunicação. Os autores argentinos que atuam nas diversas disciplinas da área aceitam o desafio de colocar sob a observação as impressões que se encontraram em relação às forças diretrizes formadas, que se manifestam nas trocas culturais, e nas experiências que se exteriorizam na sociedade. Tudo isso analisado sob a mirada da sociologia, o design de interiores, a ecologia, o design de indumentária, a fotografia, a publicidade, a arte e a pedagogia.

Palavras chave: design - tendências opostas - sociologia - design de interiores - ecologia design de indumentária - fotografia - publicidade - arte - pedagogia. 